\title{
ENTREVISTA COM O PROFESSOR DOUTOR JORGE MIRANDA
}

\section{Carlos Sérgio Gurgel da Silva}

Mestre em Direito Constitucional pela UFRN (2010). Especialista em Direitos Fundamentais e Tutela Coletiva pela Fundação Escola Supeior do Ministério Público do Rio Grande do Norte - FESMP/RN. Doutorando em Ciências Jurídico-Politicas pela Universidade de Lisboa. Professor do Curso de Direito da Universidade do Estado do Rio Grande do Norte, Campus de Natal/RN.

Autor convidado

\section{Sobre a Carreira do Professor Jorge Miranda}

O Professor Jorge Manuel Moura Loureiro de Miranda, ${ }^{1}$ mais conhecido pela comunidade acadêmica internacional como Professor Jorge Miranda, é português, nascido na cidade de Braga (norte de Portugal), em 15.04.1941. É docente da Universidade de Lisboa desde 1969-1970 e da Universidade Católica Portuguesa desde 1972-1973 e Professor Catedrático em ambas desde 19851986. Traçaremos a seguir, por oportuno, um pouco de sua carreira acadêmica.

O Professor Jorge Miranda é licenciado em Direito (1963), possui curso complementar, de Ciências Político-Econômicas (1964), e é Doutor em Direito (Ciências Jurídico-Políticas) (1979) pela Universidade de Lisboa. Na Faculdade de Direito da Universidade de Lisboa tem regido Direito Constitucional (desde o ano letivo de 1971-1972, salvo entre 1975 e 1977, período em que esteve impedido, dada a situação da Faculdade, de dar aulas), e também Ciência

1. Tomou-se como referência o curriculum vitae do Professor Doutor Jorge Miranda, disponibilizado no sítio da Internet do Instituto de Ciências Jurídico-Políticas: [http:// icjp.pt/sites/default/files/content/corpoDocente/curriculums/jm675_curriculum_vitae_2011.pdf]. 
Política, Direito Internacional Público, Direitos Fundamentais, Direito Constitucional - III, Justiça Constitucional, e (apenas no curso de mestrado) Direito Administrativo.

Foi fundador e primeiro Presidente do Instituto de Ciências Jurídico-Políticas e um dos fundadores do Instituto do Direito Brasileiro. Está ligado a diversas instituições e associações culturais e científicas, entre as quais, Associação Portuguesa de Direito do Ambiente, Associação Portuguesa de Direito Constitucional, Academia Europae (com sede em Londres), Associação Internacional para a Defesa da Liberdade Religiosa, Instituto Pimenta Bueno - Associação Brasileira de Constitucionalistas (de que é um dos presidentes de honra estrangeiros) e da Societas Iuris Publici Europei.

O Professor Jorge Miranda pertence a comissões científicas ou de redação de diversas Revistas, entre as quais: O Direito (de que foi um dos diretores adjuntos) até se tornar seu diretor em 2010, Annuaire International de Justice Constitutionnelle, European Review of Public Law, Revue française de Droit Constitutionnel, Questiones Constitucionales (do México), Revista de Direito Constitucional e Internacional (São Paulo), Revista Brasileira de Estudos Políticos, Revista Peruana de Derecho Publico, Anuario Iberoamericano de Justicia Constitucional e Direito e Cidadania (Cabo Verde).

Foi (e continua sendo) por diversas vezes homenageado nos âmbitos acadêmicos, nacional e internacional, pela extensa contribuição por si ofertada ao direito constitucional de Portugal e mundial, tendo mais de 250 obras publicadas. É doutor honoris causa pela Universidade de Pau (França), pela Universidade do Vale do Rio dos Sinos (Brasil), pela Universidade Católica de Lovaina (Bolívia), pela Unibrasil (Curitiba) e pela Universidade do Porto, sendo ainda professor honorário da Universidade Federal do Ceará. Recebeu a Comenda da Ordem de Santiago, a Grão-Cruz da Ordem da Liberdade e a Grã-Cruz da Ordem do Infante D. Henrique. Durante cerimônia de comemoração dos 100 anos da Universidade de Lisboa (em 2011) recebeu o Prêmio Universidade de Lisboa de 2011.

O Professor Jorge Miranda é conhecido também pelo seu ativismo político, principalmente às voltas da Revolução dos Cravos, ocorrida em 1974, sendo um dos grandes nomes da luta política pela redemocratização do Estado português, que culminou com a Constituição de 1976. Em 1970, foi um dos fundadores da Sedes - Associação para o Desenvolvimento Econômico e Social. Em 1974 atuou como membro da Comissão de Elaboração da Lei Eleitoral para a Assembleia Constituinte. No ano seguinte atuou como deputado à Assembleia Constituinte (1975-1976), tendo participado nas comissões de regimento, de sistematização, de organização do poder político e de redação e teve larga in- 
tervenção no plenário. De 1976 a 1980, foi membro da Comissão Constitucional (órgão antecedente do Tribunal Constitucional).

Teve participação ainda na feitura dos anteprojetos de Constituição de São Tomé e Príncipe (1990) e Timor-Leste (2002) e teve intervenções em revisões constitucionais em Moçambique (1990) e na Guiné-Bissau (1991 e 1998). Em 2010-2011 foi o comissário principal da exposição, no palácio de São Bento, sobre a Assembleia Constituinte e a Constituição de 1911.

Em síntese, o Professor Jorge Miranda é, sem dúvida, um dos maiores expoentes mundiais do direito constitucional da atualidade. Sua obra reverbera por todos os quadrantes do planeta, influenciando, em muito, o pensamento constitucional brasileiro. Até com certa frequência, atendendo a convites formulados por universidades e tribunais brasileiros, o Professor Jorge Miranda vem ao Brasil, momento em que se pronuncia, quase sempre, acerca dos problemas que o país se depara em seu amadurecimento institucional e político em face das mudanças de ordem globalizante que atingem não só o Brasil, mas boa parte do mundo ocidental. A entrevista que se segue ocorreu a uma semana da cerimônia de seu jubilamento da Universidade de Lisboa (14.04.2011), nas dependências desta mesma universidade, em Lisboa, Portugal.

Entrevista concedida ao Grupo de Pesquisa em Direitos Fundamentais e Desenvolvimento, da Universidade do Estado do Rio Grande do Norte

Data da entrevista: 07.04.2011.

Entrevistado: Professor Doutor Jorge Miranda

Entrevistador: Professor Mestre Carlos Sérgio Gurgel da Silva

Prof. Me. Carlos Sérgio: Professor, esta entrevista será concedida ao grupo de Pesquisa em Direitos Fundamentais e Desenvolvimento da Universidade do Estado do Rio Grande do Norte.

Prof. Doutor Jorge Miranda: Com todo o prazer.

Prof. Me. Carlos Sérgio: O que levou o senhor a escolher o Curso de Direito, especialmente o Direito Constitucional, como área de atuação académica e profissional?

Prof. Doutor Jorge Miranda: Desde muito jovem, me interessei, não tanto pelo Direito - que não sabia ainda bem o que era - quanto pelas Constituições. Desde muito novo, devido à minha formação religiosa, pensei que toda a atividade humana - e, portanto, também a atividade política - carecia de regras e de regras que fossem cumpridas. Ora, em Portugal, nesse tempo, a atividade política ou não estava sujeita a regras ou elas eram cumpridas distorcidamente ao serviço da ditadura (de Salazar): era o que se passava, sobretudo, com as 
liberdades e com as eleições. Eu sentia isso e sofria igualmente a influência do meu pai e de outras pessoas da minha família, que eram contra a ditadura.

Outro fator, de natureza diferente, que me conduziu ao Direito Constitucional foi o meu sempre grande gosto pela História e pela Geografia. A História e a Geografia, mostram a existência de Estados e a diversidade de regimes políticos; a História, mostrando o desenvolvimento da democracia e, mais recentemente, a vitória das democracias na 2. ${ }^{a}$ Guerra Mundial; e a Geografia, mostrando as diferenças dos Estados e da sua organização e as fronteiras.

Modéstia à parte, a partir dos 14-15 anos comecei a redigir projetos (que hoje consideraria ingénuos) de Constituição, projetos que ia, depois, sucessivamente aperfeiçoando e de que guardo ainda dois ou três.

Prof. Me. Carlos Sérgio: Que pensadores, juristas ou não juristas, mais influenciaram o senhor ao longo da sua jornada académica?

Prof. Doutor Jorge Miranda: Antes de falar nos pensadores que mais me marcaram na carreira académica, quero referir os que mais contribuíram para a minha formação democrática no sentido de uma social-democracia de base cristã: os Papas das grandes encíclicas sociais, culminando na Pacem in Terris de João XXIII (de 1963, quando eu já estava acabando o curso de Direito), o bispo D. António Ferreira Gomes, Emmanuele Mounier e, mais distantemente, para a liberdade política, os autores liberais do século XIX. Já na Universidade, o primeiro livro que li foi, por sinal, a Filosofia do Direito de Gustav Raddbruch e tornou-se-me inesquecível. E também Kant, da Paz perpétua e da Metafísica dos costumes, e Miguel Reale, que ministrou na Faculdade um importantíssimo conjunto de lições. Quanto a juristas propriamente ditos o que mais me marcou foi Marcello Caetano, que foi meu professor e meu orientador no Mestrado, e que era um grande professor respeitador da liberdade dos alunos, mesmo se, politicamente, era um Homem do regime (de que viria a ser o último Presidente do Conselho, de 1968 a 1974). E acrescento, sem esquecer Kelsen (para lá de todas as divergências), Jellinek, Hauriou, Mortati, Carlo Esposito, Karl Loewenstein, Burdeau.

Prof. Me. Carlos Sérgio: Neste tempo de incertezas, quando o fenómeno da globalização impõe inovações tecnológicas constantes, quando surgem amplas discussões sobre a relativização de valores pessoais e sociais e quando se faz um grande apelo à realização de um efetivo Estado Democrático de Direito, fala-se de um neoconstitucionalismo. Qual a sua ideia sobre o neoconstitucionalismo?

Prof. Doutor Jorge Miranda: Há um adquirido constitucional que vem do século XVIII: a Constituição, como fundamento e limite de poder, a separação de 
poderes, os direitos fundamentais, a representação política, o pluralismo. Mas há desafios novos, provocados pelos fenómenos que menciona, e ainda por mais outros, como a globalização e os riscos para o meio ambiente. E o constitucionalismo foi-se adaptando para lhes responder, ao mesmo tempo que, desde a queda de regimes totalitários e autoritários - na Itália e na Alemanha, após 1945, em Portugal e na Espanha nos anos 70, na América Latina nos anos 80, na Europa Oriental nos anos 90 - se tornou mais exigente o princípio da constitucionalidade e se afirmou a aplicação imediata da Constituição sem lei ou contra a lei. E também sob o impulso de Dworkin e Alexy, vão-se adotando conceções principialistas, que se vai tendendo a identificar as normas jusfundamentais como princípios, que se revê a doutrina da interpretação constitucional, que a ponderação vai-se sobrepondo ao método subsuntivo, que se vai falando (mais no Brasil do que na Europa) em neoconstitucionalismo.

Prof. Me. Carlos Sérgio: Como o senhor vê o papel do poder local na definição e na concretização de uma ordem constitucional garantidora dos direitos fundamentais?

Prof. Doutor Jorge Miranda: Os municípios, como elementos políticos, inclusive num Estado unitário como é Portugal, podem e devem desempenhar um papel relevante na concretização da ordem constitucional em áreas como a do urbanismo, dos espaços verdes e a preservação, em geral, do meio ambiente, dos transportes, do ensino fundamental, do apoio às famílias mais carentes, em suma, na passagem das normas para a vida concreta das pessoas. E o Estado Democrático tem de incentivar a cidadania desde os municípios e dentro dos municípios, segundo princípios de descentralização e de democracia participativa (referendo, iniciativa popular, revogação popular de mandatos, planejamento e orçamento participativos etc.). Pelo contrário, no plano das liberdades e das garantias individuais, a responsabilidade é do poder central e dos tribunais, não raro combatendo tendências de domínio local por certas famílias ou certos grupos económicos ou outros.

Prof. Me. Carlos Sérgio: Que novos rumos vislumbra o Direito Constitucional nestes tempos de relativização e de ponderação dos direitos fundamentais?

Prof. Doutor Jorge Miranda: O Direito Constitucional - ou melhor, uma Constituição verdadeiramente normativa e efetiva - é mais necessário do que nunca em face dos fenómenos que há pouco apontei, assim como de outros, muito variados: os poderes fácticos, económicos, corporativos e de interesses de vária ordem, que têm de ser submetidos ao império do Direito; em economia de mercado, a necessidade de regulação; a exclusão social, que só pode ser vencida com o incremento dos direitos sociais; o terrorismo que apenas pode ser combatido com salvaguarda da pessoa humana, porque os fins nunca 
justificam os meios. E os novos rumos para o Direito Constitucional têm de consistir, justamente, no contínuo e coerente esforço de realização de todos os direitos fundamentais, no reforço do Parlamento, na democratização interna dos partidos políticos, na celeridade das decisões dos tribunais para combate à corrupção, na responsabilização política, civil e criminal dos agentes políticos, no aprimoramento da justiça constitucional.

A integração regional - como a da União Europeia e a do Mercosul - e as organizações internacionais poderão conduzir, como alguns dizem, a um constitucionalismo de muitos níveis ou até global, mas uma coisa é certa: democracia até agora (e não antevejo que mude nas próximas décadas) somente existe no Estado e democracia ou é democracia constitucional ou não é.

Prof. Me. Carlos Sérgio: O senhor se considera um positivista? Qual a influência que os ideais jusnaturalísticos têm sobre si?

Prof. Doutor Jorge Miranda: Para responder, é preciso lembrar que a Ciência do Direito é uma ciência social normativa. Ciência social, porque estuda a sociedade; mas ciência normativa, porque a estuda através das normas que a regem. O jurista, antes de mais, toma as normas como dados, vai-as entrelaçando e vai-se elevando ao sistema e aos princípios (nisto consiste a construção dogmática). Simplesmente, como as normas têm por objeto a realidade social, o jurista não a pode desconhecer (e o constitucionalismo ignorar a realidade política). Por outro lado, com as normas são expressões de dever ser e, portanto, de valores, impõe-se olhar à circulação facto-norma-valor ou facto-valor-norma (aqui a teoria tridimensional de Miguel Reale continua utilíssima). E os valores não se reduzem aos que decorrem das transformações históricas, há valores transcendentes - como a justiça e a dignidade da pessoa humana - com as quais, criticamente, o jurista não pode demitir-se de confrontar as soluções de Direito positivo.

Serei um positivista ou jusnaturalista? Cabe a quem ler responder.

Prof. Me. Carlos Sérgio: O senhor tem viajado muito no Brasil, para conferências, congressos, cursos, e conhece bem a realidade brasileira. O que acha das políticas sociais que vêm sendo implantadas com o objetivo de reduzir as desigualdades sociais e regionais?

Prof. Doutor Jorge Miranda: Acho que são muito importantes e decisivos. Apoio e aplaudo inteiramente tudo quanto se tem realizado para fazer um Brasil para todos. A democracia não pode ser apenas política, tem de ser política, económica, social e cultural. Fora da democracia política, não há liberdade, pluralismo e alternância no poder. Tal como sem democracia económica, social e cultural, as pessoas não alcançam as necessárias condições de vida. Tudo está em congregar liberdade, cidadania e solidariedade. 
Prof. Me. Carlos Sérgio: Alguns autores falam numa Constituição europeia, outros negam que ela exista. Para o senhor existe realmente uma Constituição europeia?

Prof. Doutor Jorge Miranda: Se por Constituição se entende o conjunto das normas que estruturam uma qualquer comunidade ou organização, definindo órgãos, poderes e atos, então há uma Constituição europeia - tal como Constituição é a lei orgânica de um município ou a Carta das Nações Unidas ou até os estatutos de uma associação. Porém, desde sempre, Constituição está ligada a Estado, pressupondo um povo e um poder constituinte, e neste sentido rigoroso do termo não há uma Constituição europeia. Basta notar que a União Europeia resulta de um tratado (hoje, o Tratado de Lisboa, de 2007, celebrado por Estados e que só pôde entrar em vigor depois de a Irlanda, em segundo referendo, o aprovar) e que poderes essenciais de soberania, como os de política externa e defesa, continuam nos Estados.

Acresce que não só não existe um povo europeu como na Europa subsistem, com vigor, as nações e tem-se mesmo assistido ao recrudescimento de nacionalismos desde a Espanha (Catalunha, País Basco) à Rússia (Chechénia). E, além disso, infelizmente, a União Europeia - que tanto avançou na integração económica - ainda nem sequer conseguiu definir uma orientação segura frente à crise económico-financeira desencadeada em 2008.

Prof. Me. Carlos Sérgio: Eu ia, precisamente, perguntar em que medida a União Europeia limita a soberania dos Estados.

Prof. Doutor Jorge Miranda: Limita, sim e muito, nos aspetos económicos e financeiros, principalmente nos países que adotaram o euro. Mas, de qualquer sorte, a soberania no século XXI não pode ser como era no século XIX. Mesmo grandes Estados como os Estados Unidos, a China, a Rússia ou o Brasil sofrem fortes limitações de soberania devido ao desenvolvimento do Direito internacional (de direitos da pessoa humana, do trabalho, do ambiente etc.) e da rede crescente das organizações internacionais.

O pior está em que a União Europeia está a ser comandada pela Alemanha ou pela Alemanha e pela França, naquilo a que se tem chamado o "Diretório". Limitação de soberania, sim, mas com respeito dos princípios de igualdade como, aliás, sucede nos Estados federais. E, de resto, entre uma Europa dominada por esse Diretório e uma federação como o Brasil, eu prefiro, por todas as razões - afetivas, culturais, históricas - a federação ou a associação ao Brasil.

Prof. Me. Carlos Sérgio: O princípio da proporcionalidade é considerado por muitos um princípio "coringa", para dar tratamento diferenciado a situações diferenciadas, funcionando como um aferidor dos valores em conflito. O que pensa sobre ele? 
Prof. Doutor Jorge Miranda: O princípio da proporcionalidade, vindo do Direito Penal, adquiriu no Direito Constitucional e no Direito Administrativo um lugar centralíssimo, sobretudo quando se trate de restrições a direitos fundamentais (falando-se então em proibição de excesso) ou de incumprimento de dever de proteção. Mas não pode servir para tudo resolver, nem invocado à margem de outros princípios.

Prof. Me. Carlos Sérgio: Professor, fale-me da sua participação na elaboração da Constituição portuguesa de 1976 e na de outros países.

Prof. Doutor Jorge Miranda: Eu fui eleito Deputado à Assembleia Constituinte portuguesa de 1975-1976 e nela participei ativamente como oportunidade única de pôr à prova os meus conhecimentos e por dever cívico. Trabalhei em quatro das dez comissões: de regimento, de sistematização, de organização do poder político e de redação. Alguns chamam-me o pai da Constituição, mas não é verdade, porque outros Deputados tiveram igualmente um papel importante. E, depois da Constituição entrada em vigor, pertenci à Comissão Constitucional (o primeiro órgão específico de fiscalização da constitucionalidade no Direito português e antecedente do Tribunal Constitucional e aí contribuí para que prevalecesse uma interpretação sistemática adequada de normas constitucionais em vez de certas fórmulas ideológicas). Também tenho apresentado projetos de reforma; apresentei-os em 1980, 1997 e 2010 e, sem ter uma visão fixista do texto constitucional, sempre me tenho oposto a tentativas para o subverter.

Quanto a S. Tomé e Príncipe, foi uma honra ter-me sido confiada a elaboração do anteprojeto de Constituição em 1989, que iria permitir uma transição democrática naquele país. Na Guiné-Bissau e em Moçambique, limitei-me a intervir em debates constitucionais. Quanto a Timor-Leste, aí fui eu que ofereci um projeto a Xanana Gusmão, o qual viria a ter alguma importância na Constituição de 2002.

Prof. Me. Carlos Sérgio: Diante da crise económica por que vem passando Portugal, é necessário haver uma reforma constitucional?

Prof. Doutor Jorge Miranda: No domínio económico, a Constituição (com as revisões de 1982, 1989 e 1997) é suficientemente aberta para acolher as medidas de austeridade agora tornadas necessárias. O mesmo se diga no domínio dos direitos sociais: já hoje a Constituição, ao prever o serviço nacional de saúde, o define como tendencialmente gratuito, tendo em conta as condições económicas e sociais dos cidadãos. De resto, ir além do razoável nas medidas de austeridade poderia ter efeitos contraproducentes: por impedir o crescimento económico, indispensável para o equilíbrio tributário do Estado, e gerar uma crise social, como a que ocorre na Grécia. 
Independentemente disso, como já se disse, em 2010 publiquei (no livro de homenagem ao Prof. Sérvulo Correia) um projeto de revisão, com diferentes propostas de modificação.

Prof. Me. Carlos Sérgio: O senhor vai participar de um evento comemorativo dos 100 anos da Constituição de 1911. O que tem a dizer sobre esta Constituição?

Prof. Doutor Jorge Miranda: Essa Constituição, a primeira Constituição republicana portuguesa, é uma Constituição muito influenciada pela também primeira Constituição republicana brasileira, a de 1892. Mas a minha opinião é ambivalente. Ela trouxe alguns novos direitos fundamentais e introduziu, pela primeira vez na Europa e sob influência de Rui Barbosa, o princípio do controlo jurisdicional de constitucionalidade das leis. Em contrapartida, teve um pendor laicista e até anticatólica (ao arrepio da liberdade religiosa que consagrava em tese) e instaurou um sistema de governo parlamentar, muito instável e que, de crise em crise, iria levar em 1926 à ditadura que só terminou e 1974, 48 anos depois.

\section{Pesouisas do EditORIAL}

Veja também artigos de Jorge Miranda publicados por esta Editora

- A Constituição portuguesa e a dignidade da pessoa humana - RDCl 45/81;

- A eleição do Presidente da República em Portugal - RDCl 30/37;

- Constituição e processo civil - RePro 98/29;

- 0 veto no direito português - RDCl 17/7;

- Os direitos fundamentais - Sua dimensão individual e social - $R D C l$ 1/198;

- Os direitos políticos dos cidadãos na Constituição portuguesa - RDCl 60/299;

- Sobre as Comissões Parlamentares de Inquérito em Portugal - RDCl 33/61; e

- Sobre o direito constitucional comparado - RDCl 55/243. 